\title{
Genre and Rewritten Scripture: A Reassessment ${ }^{1}$ Molly M. Zahn, University of Kansas
}

\author{
Seeing the duck, the little bird flew down \\ upon the grass... "What kind of bird are you \\ if you can't fly?" said he. To this the duck \\ replied "What kind of bird are you if you \\ can't swim?" and dived into the pond. \\ -Sergei Prokofiev, Peter and the Wolf \\ (1936)
}

Of the many new insights provided by the Qumran materials into the textual world of Second Temple Judaism, one of the most notable has been the prominence of rewriting as a mode of textual production. Indeed, over the past thirty years or so the term "Rewritten Scripture" has come to play a key role in the study of the production, transmission, and interpretation of authoritative texts in this period. Yet as the prominence of the term has increased, debate about its exact definition and proper use has blossomed alongside. ${ }^{2}$

${ }^{1}$ This essay originated in a presentation at the $7^{\text {th }}$ IOQS meeting in Helsinki, Finland (August 2010). I am grateful for the enthusiastic feedback I received from numerous members of the audience. Subsequent drafts were read by John Collins, Peter Grund, Andrew Teeter, Ben Wright, and Amy Devitt, who also generously shared her expertise in contemporary genre theory. I thank each of these scholars for their valuable feedback; of course any errors that remain are my responsibility alone. I am also grateful to Hanne von Weissenberg for suggesting the epigraph.

${ }^{2}$ For a new overview, with bibliography, see Molly M. Zahn, "Rewritten Scripture," in The Oxford Handbook of the Dead Sea Scrolls (ed. Timothy H. Lim and 
Here I would like to focus on one aspect of this debate, whether the term "Rewritten Scripture" can be or should be used to denote a literary genre. Does Rewritten Scripture constitute a distinct category of texts, as Philip Alexander argued early on and as Moshe Bernstein has proposed recently as the most useful definition of Rewritten Scripture? ${ }^{3}$ Or are the texts usually considered Rewritten Scripture too different from one another to constitute a discrete genre, such that it is better to regard Rewritten Scripture as a procedure or technique? This position, articulated already by Daniel Harrington in 1986, has more recently found support from George Brooke and Daniel Falk. ${ }^{4}$ Anders

John J. Collins; Oxford: Oxford University Press, 2010), 323-36. See also the recent review essay by Daniel A. Machiela, "Once More, with Feeling: Rewritten Scripture in Ancient Judaism—A Review of Recent Developments," JJS 61 (2010): 308-20; and Molly M. Zahn, "Talking about Rewritten Texts: Some Reflections on Terminology," in Changes in Scripture: Rewriting and Interpreting Authoritative Traditions in the Second Temple Period (ed. Hanne von Weissenberg et al.; BZAW 419; Berlin: De Gruyter, 2011), 93-119.

${ }^{3}$ Philip S. Alexander, "Retelling the Old Testament," in It Is Written: Scripture Citing Scripture (ed. D. Carson and H.G.M. Williamson; Cambridge: Cambridge University Press, 1988), 99-121; Moshe J. Bernstein, “'Rewritten Bible’: A Generic Category Which Has Outlived Its Usefulness?,” Textus 22 (2005): 169-96.

${ }^{4}$ Daniel J. Harrington, "Palestinian Adaptations of Biblical Narratives and Prophecies I: The Bible Rewritten (Narratives)," in Early Judaism and Its Modern Interpreters (ed. Robert A. Kraft and George W. E. Nickelsburg; Philadelphia: 
Klostergaard Petersen has suggested a sort of intermediate position, proposing that Rewritten Scripture would not have been a meaningful generic category to ancient Jewish writers and audiences, but that it can function as an important category for modern scholars concerned with charting the various types of relationships between works that ended up in the Hebrew Bible and works related to them in some way. ${ }^{5}$

Fortress/Atlanta: Scholars, 1986), 239-47, at p. 243; George J. Brooke, "Rewritten Bible," in Encyclopedia of the Dead Sea Scrolls (ed. Lawrence H. Schiffman and James C. VanderKam; Oxford: Oxford University Press, 2000), 777-81; Daniel K. Falk, The Parabiblical Texts: Strategies for Extending the Scriptures in the Dead Sea Scrolls (Companion to the Qumran Scrolls 8; London: T\&T Clark, 2007), 17. Note that, more recently, Brooke has suggested that perhaps the issue is not so much one of "genre" vs. "technique" or "strategy," but of what Brooke terms "hierarchies of genre": generic categories that function at different levels of abstraction; George J. Brooke, "Genre Theory, Rewritten Bible and Pesher," DSD 17 (2010): 361-86, at pp. 369, 375-79, and especially 372 n. 30. Elsewhere, Brooke has referred to Rewritten Bible as a "metagenre": George J. Brooke, "The Books of Chronicles and the Scrolls from Qumran," in Reflection and Refraction: Studies in Biblical Historiography in Honour of A. Graeme Auld (ed. Robert Rezetko et al.; VTSup 113; Leiden: Brill, 2007), 35-48, at pp. 41, 47. See also John J. Collins, "Epilogue: Genre Analysis and the Dead Sea Scrolls," DSD 17 (2010): 418-30, at p. 428. On this issue, see further below.

${ }^{5}$ Anders Klostergaard Petersen, "Rewritten Bible as a Borderline PhenomenonGenre, Textual Strategy, or Canonical Anachronism?," in Flores Florentino: Dead Sea 
The debate about genre and Rewritten Scripture has already called attention to numerous important issues. In my view, however, something has been missing from this discussion until very recently. On the one hand, there has been little explicit consideration of what exactly a "genre" is, and what difference it would make if Rewritten Scripture was one. On the other hand, there has also been little interaction with the writings of those whose work might help us answer those questions, namely genre theorists. ${ }^{6}$ In this respect the study of Rewritten Scripture has not differed from the rest of Qumran scholarship or, indeed, from much of biblical studies in general: as Carol Newsom notes, despite periods of great interest in the issue of genre within biblical scholarship and important work on genre by individual scholars, "the conversation between biblical studies and genre studies continues to be sporadic."7

For Qumran studies, this situation has changed somewhat even in the course of my work on this topic: the November 2010 volume of Dead Sea Discoveries is dedicated Scrolls and Other Early Jewish Studies in Honour of Florentino García Martínez (ed. Anthony Hilhorst, Émile Puech, and Eibert Tigchelaar; JSJSup 122; Leiden: Brill, 2007), 285-306, at pp. 303-5. Similarly, see Machiela, “Once More, with Feeling,” 318.

${ }^{6}$ Petersen's 2007 essay constitutes the exception on both of these scores, as he does consider more explicitly what he means by "genre" and interacts in a preliminary way with genre theory. See Petersen, "Rewritten Bible," 302-5.

${ }^{7}$ Carol A. Newsom, "Spying Out the Land: A Report from Genology," in Bakhtin and Genre Theory in Biblical Studies (ed. Roland Boer; Semeia Studies 63; Atlanta: Society of Biblical Literature, 2007), 19-30, at p. 20. 
to the issue of genre, and most of the contributors explicitly engage recent trends in contemporary genre theory. Contributions by George Brooke and John Collins deal specifically with the issue of Rewritten Scripture, while several other articles discuss genre in ways that are potentially applicable to Rewritten Scripture. ${ }^{8}$ Here I would like to build on this promising beginning by offering some further reflections on Rewritten Scripture in light of contemporary genre theory. While I draw partly on the same literary genre theorists as the contributors to the $D S D$ volume, I will also consider developments in the study of genre within the field of rhetoric, as opposed to literary studies. ${ }^{9}$ As I will demonstrate, the insights of various branches of modern genre theory provide at least a possible resolution to the debate over whether, and in what way, Rewritten Scripture should be considered a genre. More importantly, engagement with this type of work allows us to articulate more clearly the significance of the genre question, and thus helps us to a better understanding of the texts themselves and their place in Second Temple Judaism.

\section{The Case Against Rewritten Scripture as a Genre}

\footnotetext{
${ }^{8}$ Brooke, "Genre Theory"; Collins, "Epilogue" (see n. 4 above). See also especially the contributions to the same volume by Benjamin Wright and Robert Williamson.

${ }^{9}$ For a lucid explanation of the differences in approach between rhetorical and literary genre theorists, see Amy J. Devitt, Writing Genres (Carbondale, Ill.: Southern Illinois University Press, 2004).
} 
The basic question to be investigated here is what, if anything, binds together those texts that scholars have identified as Rewritten Scripture, and whether their commonalities are such that this group of texts might constitute something we could call a "genre." Of course, membership in this group is a matter of dispute: nearly every scholar who operates with an idea of Rewritten Scripture as a genre has a different list of which texts deserve that generic label. ${ }^{10}$ In the first instance, however, the boundaries of Rewritten Scripture as a category are of secondary concern for us, the main issue being whether Rewritten Scripture constitutes a distinct category at all and, if so, what kind. Despite the widespread - though contested — opinion or assumption that Rewritten Scripture is a literary genre, there are some evident problems with such a claim. This is especially true if we are operating, as seems usually to have been the case, with a traditional notion of genre as a clearly demarcated textual category identified by the presence of specific and distinctive formal features. ${ }^{11}$

The most obvious problem is that the feature that most people have regarded as constitutive of Rewritten Scripture is the sustained redeployment of a previously-existing scriptural text with the incorporation of various types of major and minor alterations. This

${ }^{10}$ For an overview of the different proposals, see Bernstein, "Rewritten Bible."

11 The idea of genre as identified primarily by formal textual features has a long history within biblical studies as well as in other fields; see Newsom, "Spying Out the Land," 20-21; Devitt, Writing Genres, 6-11; Alastair Fowler, Kinds of Literature: An Introduction to the Theory of Genres and Modes (Cambridge, Mass.: Harvard University Press, 1982), 38-40. 
feature, of course, is not limited to any one literary genre as we are used to thinking about them. Insofar as Jewish Scripture of the Second Temple period comprised various genres - e.g., legendary narratives, laws, historiography, prophetic visions and oracles, and other types of poetry - a given text classified as Rewritten Scripture could belong to any one of these genres. ${ }^{12}$ Thus, of texts usually agreed to represent Rewritten Scripture, we have rewritings of pentateuchal narrative (Jubilees and the Genesis Apocryphon), pentateuchal law (the Temple Scroll), and historiographic narrative (Chronicles). The biblical portions of Josephus's Antiquities cover all three of these genres. Examples of rewritten prophetic, poetic, and sapiential texts are less widely agreed upon, but texts like Pseudo-Ezekiel (4Q385-386, 388, 391), the Words of the Luminaries (4Q504, 506), and the Non-Canonical Psalms (4Q380-81) all incorporate large amounts of scriptural material and should at least be considered possible examples. ${ }^{13}$ The main point, though, is that calling a text Rewritten Scripture says nothing a priori about that text's structure or contents. There are not specific themes or formal features we could look for to decide

${ }^{12}$ Brooke, "Rewritten Bible," 780: "Rewritten Bible texts come in almost as many genres as can be found in the biblical books themselves."

${ }^{13}$ On the use of Scripture in the Words of the Luminaries, see Esther G. Chazon, "Scripture and Prayer in 'The Words of the Luminaries," in Prayers That Cite Scripture (ed. James L. Kugel; Cambridge, Mass.: Harvard University Press, 2006), 25-41. On Pseudo-Ezekiel, see Monica Brady, "Biblical Interpretation in the 'Pseudo-Ezekiel' Fragments (4Q383-391) from Cave Four," in Biblical Interpretation at Qumran (ed. Matthias Henze; Grand Rapids: Eerdmans, 2005), 88-109. 
whether a text belonged in the genre, as one might do for apocalypses or wisdom texts (to name two categories that have generated considerable interest from a genre perspective).${ }^{14}$ Instead, the "rewritten" label is predicated upon the relationship of a given text to an earlier text. In effect, it is based on a judgment about the compositional history of a work rather than directly upon formal features of the work itself. Can a common means of composition really constitute sufficient reason to view texts with disparate contents and structures as belonging to a single genre?

A second difficulty is that even some of the "classic" examples of Rewritten Scripture incorporate major sections in which there is no sustained interaction with a scriptural base text. Jubilees is the work that perhaps follows its scriptural base most closely, and even it sometimes adds whole chapters of new material. ${ }^{15}$ Many of the earlier columns of the Genesis Apocryphon represent expansions with no pentateuchal parallel, and the same can be said for parts of the Temple Scroll, like the instructions for the Temple courts. Can there be a genre called Rewritten Scripture if very few works are completely constituted through rewriting?

Finally, recent studies have made clear that the techniques used to reconfigure the scriptural text in works usually labeled Rewritten Scripture are fundamentally the same as

${ }^{14}$ On these two categories, see Benjamin G. Wright III, "Joining the Club: A Suggestion about Genre in Early Jewish Texts," DSD 17 (2010): 289-314.

${ }^{15}$ E.g. the majority of ch. 1, describing previously unknown words of God to Moses on Sinai; the expansions to the Abraham story in chs. 11-12, 20-22; or the eschatological material in ch. 23. 
those used to produce revised versions of the scriptural texts themselves; that is, new copies of scriptural books. ${ }^{16}$ More broadly speaking, David Carr in particular has demonstrated the extent to which revision and reconfiguration of earlier works was a standard mode of literary production in the ancient world. ${ }^{17}$ If the rewriting that is constitutive of the category Rewritten Scripture is something that simply took place in the course of the scribal transmission of sacred texts - or, indeed, of any texts - how can Rewritten Scripture be identified as a separate genre primarily on the basis of that rewriting?

${ }^{16}$ See e.g. Eugene Ulrich, "The Text of the Hebrew Scriptures at the Time of Hillel and Jesus," in Congress Volume Basel 2001 (ed. Andre Lemaire; VTSup 92; Leiden: Brill, 2002), 85-108, at pp. 102-3; James C. VanderKam, “Questions of Canon Viewed through the Dead Sea Scrolls," in The Canon Debate (ed. Lee Martin McDonald and James A. Sanders; Peabody, Mass.: Hendrikson, 2002), 91-109, at pp. 96-100; Michael Segal, "Between Bible and Rewritten Bible," in Biblical Interpretation at Qumran (ed. Matthias Henze; Grand Rapids: Eerdmans, 2005), 10-29; Sidnie White Crawford, Rewriting Scripture in Second Temple Times (Grand Rapids: Eerdmans, 2008), 12-15; Molly M. Zahn, Rethinking Rewritten Scripture: Composition and Exegesis in the 4QReworked Pentateuch Manuscripts (STDJ 95; Leiden: Brill, 2011).

${ }^{17}$ David M. Carr, Writing on the Tablet of the Heart: Origins of Scripture and Literature (New York: Oxford University Press, 2005), especially 34-46, 228-38. 
On the face of it, then, there seem to be plenty of reasons not to speak of even a small core group of texts as constituting a "genre" called Rewritten Scripture. But seen in the light of recent developments in genre theory, the issues are not so straightforward.

\section{Genre Theory and Rewritten Scripture}

Genres have historically tended to be viewed, within biblical studies as well as in other fields, as tools for classification of texts, with each genre constituting, in essence, a box or pigeonhole into which texts with the same characteristics could be placed. For inclusion in a given pigeonhole, a text should possess distinct, defined characteristics of form, structure, and theme. As the famous genre theorist Alastair Fowler notes, however, this view of genres as mutually exclusive and possessing certain "necessary elements" tends to break down in the face of real texts, which frequently appear to mix genres, omit apparently essential features of a genre, add other, unexpected features, and so on. ${ }^{18}$ Newer ideas about genre, as a result, have tended to move away from strictly classificatory or taxonomic approaches and the "in or out," binary logic that they entail. ${ }^{19}$ Instead, genres are increasingly construed as essential tools for communication and meaning-making; in one formulation, "as contracts between writers and readers, laying out common expectations for what the text in question is intended to do and what means

\footnotetext{
${ }^{18}$ Fowler, Kinds of Literature, 37-41.

${ }^{19}$ See Newsom, "Spying Out the Land," 26.
} 
it is likely to use." 20 The notion of "category" or "classification" remains important, since at the root of the idea of genre are the processes by which humans perceive similarity and difference, and by which items perceived as similar are associated with one another in groups ${ }^{21}$ But theorists have highlighted how flexible such groupings can be, changing diachronically and synchronically in accordance with variations in the perspectives and goals of both author and audience. Three aspects of recent work on genre seem particularly significant to me in thinking about Rewritten Scripture: the element of generic flexibility; the idea that genres change over time and are inevitably related to other genres; and the rhetorical notion of genres as patterns of action.

\section{The Flexibility of Genres}

In recent years, increasing stress has been placed on the flexibility of genres. Fowler, in an oft-cited remark, makes this point by noting that genres are less like pigeonholes and

\footnotetext{
${ }^{20}$ Carol Newsom, "Rhetorical Criticism and the Dead Sea Scrolls," in Rediscovering the Dead Sea Scrolls: An Assessment of Old and New Approaches and Methods (ed. Maxine L. Grossman; Grand Rapids: Eerdmans, 2010), 198-214, at p. 199. ${ }^{21}$ See the important article by Michael Sinding, "After Definitions: Genre, Categories, and Cognitive Science," Genre 35 (2002): 181-219. Sinding's work with the notion of "prototypes" (first developed within the field of cognitive science) is discussed in relation to early Jewish texts by Newsom, "Spying Out the Land," 24-26; Wright, "Joining the Club," 292-95; and especially Robert Williamson, Jr., "Pesher: A Cognitive Model of the Genre," DSD 17 (2010): 336-60.
} 
more like pigeons. ${ }^{22}$ I think the point is better illustrated, however, by saying that genres might be regarded as flocks of pigeons, with the individual texts associated with a genre represented by the individual birds in the flock. Just as a flock of pigeons might change shape, lose and add members, be absorbed into larger flocks or break apart into several smaller flocks, genres and their boundaries are not static. ${ }^{23}$ Furthermore, just as pigeons can fly off on their own or join another flock or go back and forth between flocks, texts are no longer seen as "belonging" to a single genre. Instead, we can speak of texts "participating" in genres: dipping into them, employing their elements in modified fashion, combining them. ${ }^{24}$ In this model, texts can participate in multiple genres simultaneously.

${ }^{22}$ Kinds of Literature, 37.

${ }^{23}$ My modification of Fowler's metaphor to involve "flocks of pigeons" has been met by the friendly objection from several quarters that pigeons do not form flocks. The ornithologically curious might consult Phil Berardelli, “When Pigeons Flock, Who's in Command?," ScienceNOW, April 8, 2010 (http://news.sciencemag.org/sciencenow/2010/04/when-pigeons-flock-whos-incomma.html, accessed 7 January 2011), and the Hungarian study upon which the popular article is based: Máté Nagy et al., "Hierarchical Group Dynamics in Pigeon Flocks," Nature 464 (April 8, 2010): 890-93. I am grateful to Andrew Teeter for pointing me to these references.

${ }^{24}$ The language of participation as opposed to belonging, or "participation without belonging," originates with Jacques Derrida, "The Law of Genre," Critical 
Pigeons can serve to make one further point relative to generic flexibility. An observer of a flock of pigeons could separate the individual birds into groups based on a variety of criteria: color, size, number of fleas, whether they were missing any flight feathers, etc. Different birds (= texts) would end up in different groups depending upon the criterion used to sort them. In the same way, as the genre scholar Amy Devitt stresses, how individual texts are grouped into genres depends a great deal upon who is doing the grouping and what features they are paying attention to: theme, style, structure, poetic meter, etc. ${ }^{25}$

This flexibility allows for the possibility that Rewritten Scripture could constitute a genre despite the difficulties I mentioned above. It would not necessarily matter that Rewritten Scripture compositions can be placed into other groups, such as narrative or Inquiry 7 (1980): 55-81, at p. 59. The first part of this essay is conveniently available in the anthology Modern Genre Theory (ed. David Duff; Harlow: Longman, 2000), 219-31. While Derrida views the fact of texts' "participation without belonging" to a genre as an indication of the way in which markers of a text's participation in a genre inevitably lead to the "degenerescence" of that genre ("Law of Genre," 66), Cohen offers a valuable corrective by noting that what Derrida refers to as "degenerescence" and "end" can be viewed from another angle simply as change over time: genres are not fixed essences that die when they are changed, but fluid entities that are redefined as circumstances require. See Ralph Cohen, “History and Genre,” New Literary History 17 (1986): 203-18, at pp. 204-6, 210.

${ }^{25}$ Devitt, Writing Genres, 7. 
even apocalypse for Jubilees or law for the Temple Scroll. Their rewriting of prior Scripture - perhaps in conjunction with other shared characteristics - could constitute sufficient reason to consider Jubilees and the Temple Scroll and others as also participating in a distinct genre called Rewritten Scripture. One would not have to decide, for instance, whether the Temple Scroll should belong to the genre "law" or the genre "Rewritten Scripture": it could belong to both. ${ }^{26}$ A more flexible idea of genre also accommodates the observation that many texts, even those often regarded as parade examples of Rewritten Scripture, like the Temple Scroll and the Genesis Apocryphon, seem to consist only partly of sustained scriptural rewriting. If texts can participate in multiple genres and creatively play with and combine different genres, then perhaps it is to be expected that different texts would not all participate in or make use of a hypothetical genre Rewritten Scripture in the same way or to the same extent.

This idea that some texts in effect constitute "better" or "clearer" examples of a genre than others is consistent with the concept of "prototypes," which derives ultimately from cognitive science and which Newsom, Wright, and Williamson have used productively in their own studies of genre in Second Temple literature. ${ }^{27}$ The basic thrust of this concept is that humans do not conceive of categories or decide whether a given object belongs to a given category by means of a checklist of features, but rather by

${ }^{26}$ I am grateful to John Collins for his comments on this issue.

${ }^{27}$ See $\mathrm{n} .21$ above. The following description draws heavily on Wright, "Joining the Club," 292-93. I am grateful to Prof. Wright for sharing a copy of this article with me prior to its publication. 
comparison to some object that is taken as prototypical. ${ }^{28}$ The classic example given by prototype theorists is birds: we do not identify birds by making a list of the things that identify them as birds (wings, feathers, hollow bones, etc.), but by comparing the potential bird to a prototypical bird—for those of us from Europe or North America, as Wright suggests, probably something like a robin or a sparrow. Birds that differ greatly from sparrows or robins, like storks or emus or penguins, are still recognized as belonging to the category, but less obviously than the prototypical members: they are less good examples of the category. By the same token, a text like Jubilees, with its very consistent engagement with the scriptural text, might constitute, for us at least, a prototypical example of Rewritten Scripture, while texts that are less consistent in their scriptural reuse could still participate in or make use of the genre, but to a lesser degree than Jubilees. ${ }^{29}$

${ }^{28}$ For the development of this theory, see the works referenced by Sinding, "After Definitions," 185 n. 9.

${ }^{29}$ This last sentence points to a limit to the analogy between the category "birds" and a generic category like "Rewritten Scripture": an animal cannot, scientifically, "participate in" or "make use of" the category "bird": it is either a bird or it is not. That is, "bird" is a category with definite boundaries. (We should remember, though, that human perceptions of these boundaries can change: the Priestly authors of Leviticus, after all, included the bat in the category of birds.) Genres, on the other hand, belong to a group of categories that lack fixed boundaries, in which an item can be a fuller member of the category or only partially a member. Other categories of this type would include, 


\section{Genres in Historical Perspective}

The second aspect of modern genre theory that I want to highlight is the relational and historical aspect of genres. This is an idea that can be traced back to the work of the Russian Formalists in the early part of the twentieth century and has been elaborated upon by scholars like Ralph Cohen and Hans Jauss. ${ }^{30}$ Genres are not somehow pure essences that exist in and for themselves; rather, they are groupings of texts that emerge in particular historical and social contexts in relation to already-existing forms of discourse. As Cohen puts it, "[a] genre does not exist independently; it arises to compete

or to contrast with other genres, to complement, augment, interrelate with other genres." ${ }^{\prime 31}$ The aspect of relationship to a prior genre as integral to the identity of a new genre captures nicely the issue of the relationship between the rewritten work and the work it rewrites that lies at the heart of the idea of Rewritten Scripture.

\section{Genre as Action: The Functional Aspect of Genre}

for example, colors (an object can be more blue than another object). My analysis here draws upon Daniel Boyarin's lucid discussion in Border Lines: The Partition of JudaeoChristianity (Philadelphia: University of Pennsylvania Press, 2004), 24-25. Boyarin, in turn, draws on the work of linguist George Lakoff, Women, Fire, and Dangerous Things: What Categories Reveal About the Mind (Chicago: University of Chicago Press, 1987).

${ }^{30}$ See Cohen, "History and Genre”; Hans Jauss, "Theory of Genres and Medieval Literature," in idem, Toward an Aesthetic of Reception (trans. Timothy Bahti; Minneapolis: University of Minnesota Press, 1982), 76-109.

${ }^{31}$ Cohen, "History and Genre," 207. 
Finally, a third promising aspect of genre theory is the idea of genre as action. Within the field of rhetoric in particular, genre has come to be construed as a pattern of responses that both an author and an audience will recognize as called for in a given situation. ${ }^{32}$ This idea of genre as typified action in response to similar situations can easily been grasped if we think of genres like the newspaper open letter, or the eulogy, or the closing statement of a defense attorney in a courtroom: customs and conventions have developed for language use in these situations, language users know to employ these conventions, and audiences know how to understand and process them. ${ }^{33}$ It is not the case in this model that genres lack formal or thematic features that identify them; rather, the key element of the genre is the rhetorical or communicative action that the use of those features accomplishes. ${ }^{34}$

The rhetorical origins of this approach are clear, and one can easily imagine the difficulties that could emerge in applying it to the study of more complex literary genres: what, for example, is the precise "situation" to which a novel is the appropriate and

${ }^{32}$ See especially Devitt, Writing Genres, 12-14, and the literature cited there. Devitt stresses the importance of the work of Carolyn Miller to the development of this model of genre over the last several decades; see Carolyn R. Miller, "Genre as Social Action," Quarterly Journal of Speech 70 (1984): 151-67.

${ }^{33}$ Devitt, Writing Genres, 13-14.

${ }^{34}$ As Devitt notes, some genres are more heavily bound to specific formal features, while the individual members of other genres differ widely in form (Writing Genres, 10). 
expected response? ${ }^{35}$ But some genre theorists who focus on literary texts have adopted similar models, focusing on the function of various genres in the various situations in which they occur. ${ }^{36}$ As noted above, these theorists stress that genres are not simply systems of classification developed and used by literary critics, but are fundamental to all human communication, including literature. As Fowler puts it, for example, genres are instruments, "not of classification or prescription, but of meaning"- they are used, reproduced, and manipulated by authors to communicate in specific ways with their audiences. ${ }^{37}$ When we think about genre with regard to Rewritten Scripture, therefore, we

${ }^{35}$ Devitt, Writing Genres, 14-15.

${ }^{36}$ See especially Beebee's idea of "use-value," by which he means that the defining characteristic of a given genre is what works belonging to that genre do for their readers; what function they have in the lives of their audiences. While the concept of "use-value" would seem to imply a heavily reader-oriented approach to genre (see Brooke, "Genre Theory," 374), Beebee in fact stresses the key role played by genre systems in the production of texts, as authors both are influenced by and exploit the expectations surrounding the use-values of various genres: "Primarily, genre is the precondition for the creation and the reading of texts." Thomas O. Beebee, The Ideology of Genre: A Comparative Study of Generic Instability (University Park, Penn.: Pennsylvania State University Press, 1994), 250; see also pp. 3-19 and Fowler, Kinds of Literature, 38. For a helpful comparison of rhetorical and literary genre theory, and a discussion of the common ground between the two, see Devitt, Writing Genre, 163-90.

${ }^{37}$ Fowler, Kinds of Literature, 22. 
are not simply asking questions pertaining to classification. Rather, the genre question raises issues that go to the heart of what we seek to know about these works: Why were they produced? What did their authors hope to accomplish? How did their authors intend them to be read? If we decide, in other words, that Rewritten Scripture constitutes a distinct genre, we are suggesting that something was gained or something specific could be communicated - a specific goal could be accomplished - by the use of this genre as opposed to a different one.

It should also be clear that this idea of genre emphasizes the community and social setting in which the text originates. If genre is defined as a typified action, as a way in which an author or language-user responds to a given situation, or as a means for communication and meaning-making, then it follows that genre must be meaningful at the level of the author and the audience. In other words, this approach implies that the "genre" of a Second Temple period text properly denotes a category or pattern that would have been recognizable to Second Temple writers and/or their audiences, not simply a category that we modern scholars have developed for our own heuristic purposes. ${ }^{38}$

${ }^{38}$ Although some modern theorists, e.g. Adena Rosmarin in her 1985 book The Power of Genre (University of Minnesota Press), would argue that genre is a category determined entirely for and by the critic — thus, as Beebee notes, removing from both author and original audience any concern with genre (Ideology, 254) — this idea is inimicable to the entire enterprise of rhetorical genre theory, concerned as it is with strategies for communication. Even though, as Devitt shows, literary genre theorists tend to focus more heavily on the readers of a text than on its producers, prominent theories of 
Obviously, this means that study of the genre of Second Temple texts entails a process of historical reconstruction, and that we run the constant risk of equating our own perspectives with those of ancient Jewish communities: after all, historical reconstruction begins from our own readings of ancient texts and material evidence. Yet this is no different from any other aspect of the contemporary study of early Judaism (and study of the ancient world in general). Just as we seek to recover ancient Jewish perspectives and practices in a whole variety of elements of religion and society, we can attempt to determine ancient Jewish expectations and attitudes regarding genre. ${ }^{39}$

genre such as that outlined by Fowler (see above) emphasize genre as a means of communication or conveyance of meaning and thus see genre systems as involving producers as well as consumers of texts; therefore they likewise call into question the one-sided view of genre as solely the tool of the later critic. On the relative emphasis in different branches of genre theory on the role of the reader or critic vs. the role of the author, see Devitt, Writing Genres, 169-72.

${ }^{39}$ Some have argued that, because we have no examples of explicit theorizing of or reflection upon genre from any strand of ancient Judaism, we must recognize that genre categorization is only a modern issue that does not reflect ancient concerns; see Collins, "Epilogue," 421; similarly, Timothy Lim, Pesharim (CQS 3; London: Sheffield Academic Press, 2002), 40, 52-53. Behind the various approaches to genre discussed here, however, lies the common thread that genre is in fact inherent in every text, since genre systems are crucial to any text's communicative function. Thus, genre systems are present and operative whether or not they are explicitly identified or theorized. See e.g. 


\section{Posing the Question Anew: Is Rewritten Scripture a Genre?}

To sum up thus far, all these observations stemming from modern genre theory allow us to reframe the question about Rewritten Scripture and genre. Issues like diversity in content and form, or differences in the extent of rewriting, need not preclude the identification of Rewritten Scripture as a genre. Given the degree to which genres inevitably constitute a response to existing genres, it seems at least possible to view the rewriting of a text already regarded as authoritative as the key feature of a distinct genre. Furthermore, the emphasis on function in recent genre study suggests that we should be looking for evidence of another sort of shared feature if we are to regard Rewritten Scripture as a genre: Do these texts all $d o$ the same thing? Is there a degree to which the rewriting in these texts constitutes a meaningful action that accomplishes a certain goal? If we can find evidence that some or all of the compositions usually considered Rewritten

Fowler, Kinds of Literature, 24; Beebee, Ideology, 250; Devitt, Writing Genres, 166. Williamson cites research showing how even very young children are able to distinguish between different television genres as evidence that "genre distinctions function in organizing and interpreting information even in populations in which genre categories themselves may not be explicitly recognized as such"; see Williamson, "Pesher: A Cognitive Model,” 352-53. 
Scripture "act" or function in a particular way, then we are probably justified in referring to a genre called Rewritten Scripture. ${ }^{40}$

The question, of course, now becomes: can we identify any such distinctive function or action? Perhaps even when we reframe the genre question in this way, the various texts that rewrite Scripture are just too different from each other in their functions and purposes; or perhaps anything that unifies them is so vague as to be unhelpful, or does not constitute the kind of commonality that should be designated with the term "genre." ${ }^{41}$ Nevertheless, I think that there are elements common to some of these texts

${ }^{40}$ Brooke, responding primarily to Beebee's work, similarly suggests that "the way texts work for their first or implied readers and hearers, their function, also needs to be considered" in genre analysis ("Genre Theory," 375).

${ }^{41}$ Concerns such as these are expressed by Collins ("Epilogue," 425-26), who observes, first, that function or purpose can be difficult to determine and, second, that there is no necessary correlation between form and function; that is, perhaps "texts that share a literary form and/or specific content” could have had different functions. With regard to Collins's first point, purpose/function undoubtedly is more difficult to determine than, say, literary structure or poetic meter. Given that function has come to be seen by many as an important aspect in or even the defining feature of some genres, however, it seems necessary to attempt to bring function into the discussion, despite the difficulties. I am in agreement with Collins on his second point, that there is no necessary correlation between form and function (although, of course, we often have no other evidence for an ancient text's function than what we can deduce from the features of that 
that do point to a reasonably distinct profile in terms of what these texts are trying to accomplish. These elements go beyond the mere fact of rewriting: not every text that reconfigures earlier Scripture has the features that point to this distinctive profile. Yet at least a core group of rewritten texts seems to use rewriting in specific ways that, I believe, allow us to sketch the contours of a distinct genre. The three elements that strike me as most crucial are, first: status as a new work (as opposed to a copy of a biblical book); second: a concern with interpretation of specific scriptural passages; and third: the

text). Where we perhaps differ is in the interpretation of the significance of this observation. I would not regard similarity of form or even of content as necessarily requiring that two texts belong to a single genre. This point can be illustrated by considering parodies of established modern genres in media such as film, television, and music. For instance, the popular American television show "The Daily Show" looks like it belongs to the genre we could call "television news program"; that is, it contains extensive structural and content parallels with that genre. However, most viewers, as well as the show's creators, would perceive "The Daily Show" as belonging to a different genre, "satire." I would argue that e.g. the book of Genesis and the book of Jubilees similarly have major overlaps in structure and content, but can be construed as belonging to two different genres. Conversely, difference in form does not preclude a common function, and thus participation in the same function-based genre: "The Daily Show" and Gulliver's Travels can both be grouped together into the genre "satire." (I thank John Collins for raising this last issue.) 
situating of the new work as part of the same "discourse" or "stream of tradition" as the original work that formed the basis of the rewriting.

With the first element, I simply mean that scribes who produce new rewritten compositions that have their own structure and integrity are doing something different from scribes who produce expanded copies of biblical books, even though both sometimes use similar techniques of revision and rewriting. ${ }^{42}$ It would be overly reductive to try to give some general explanation of why a Second Temple scribe or scribes decided to compose a new work, other than to say that it seems obvious that, consciously or unconsciously, such a scribe must not have felt that producing a new edition of an existing authoritative text provided sufficient latitude to say whatever it was the scribe had to say.

With the second element, the element of interpretation, I mean that sustained rewriting of the type we see in Jubilees, the Temple Scroll, the Genesis Apocryphon, Josephus, and also perhaps in a text like Pseudo-Ezekiel always involves a great deal of interpretation. The reproduction of specific verses with changes of various kinds

${ }^{42}$ Especially given the fragmentary condition of many Qumran manuscripts, it can sometimes be difficult to determine whether a given text constitutes an expanded copy of an earlier text or a new, rewritten composition. The best clues that a given text represents a new composition are found in literary features such as changes to the narrative voice, scope, or setting of the text. See Michael Segal, "Between Bible and Rewritten Bible," in The Bible at Qumran (ed. Matthias Henze; Grand Rapids: Eerdmans, 2005), 10-29; Zahn, Rethinking Rewritten Scripture, 7-11, 236-39. 
constitutes an implicit interpretive comment upon the older text. To mention just one of hundreds of possible examples, Jubilees makes slight modifications to the scene of Adam's naming of the animals in Genesis 2 to make clear that God of course knew all along that none of the animals would be an appropriate partner for the man, something that is not clear from the text of Genesis. ${ }^{43}$ This degree of interpretive engagement is not found in compositions that do not employ such sustained rewriting. Even those related in some way to scriptural characters and themes, such as 1 Enoch, do not engage in scriptural interpretation to nearly the same degree, unless scriptural interpretation is defined very broadly. (1 Enoch or at least the Book of Giants could certainly be viewed in some way as an "interpretation" of the brief notice about the Watchers in Gen 6:1-4, but to me this is much different from the sustained interpretation of a succession of specific scriptural texts that we see in Jubilees and the Temple Scroll.) In other words, continuous scriptural rewriting enables or facilitates interpretation.

Of course interpretation could occur in other formats in the Second Temple period, notably through changes made to copies of the scriptural text itself, or through explicit interpretation of the type found in 4QMMT or the pesharim. This is where the third element comes in. Most of the texts usually discussed as Rewritten Scripture present themselves as the same basic type of text-as belonging in some way to the same "discourse" - as the texts they rewrite. Here I use the term "discourse" in the sense that Hindy Najman talks about "Mosaic discourse": a textual tradition with a certain pedigree

${ }^{43}$ On this interpretation, and for many more examples, see James L. Kugel, Traditions of the Bible (Cambridge, Mass.: Harvard University Press, 1998), 113. 
within which new texts could seek to locate themselves. ${ }^{44}$ Thus, for example, as Najman shows, Jubilees and the Temple Scroll each position themselves within the discourse constituted by the Mosaic Torah. ${ }^{45}$ Similarly, Chronicles embodies the same sort of discourse as Samuel-Kings; and Pseudo-Ezekiel the discourse of what became the biblical book of Ezekiel. This self-location within an existing discourse can be accomplished through changes that introduce a pseudepigraphic element, as in Jubilees and the Temple Scroll, or it can be accomplished through lack of change- through reproduction and extension of the voice and style of the original text — as in Chronicles

${ }^{44}$ Hindy Najman, Seconding Sinai: The Development of Mosaic Discourse in Second Temple Judaism (JSJSup 77; Leiden: Brill, 2003); “Reconsidering Jubilees: Prophecy and Exemplarity," in eadem, Past Renewals: Interpretative Authority, Renewed Revelation and the Quest for Perfection in Jewish Antiquity (JSJSup 53; Leiden: Brill, 2010), 189-204. On the centrality of this feature in texts that rewrite Scripture, see George J. Brooke, "Between Authority and Canon: The Significance of Reworking the Bible for Understanding the Canonical Process," in Reworking the Bible: Apocryphal and Related Texts at Qumran (ed. Esther G. Chazon, Devorah Dimant, and Ruth Clements; STDJ 58; Leiden: Brill, 2005), 85-104, at p. 98. In his recent article on genre, Brooke suggests that the predominance of this feature should be taken into account in any attempt to define or delineate a genre called "Rewritten Scripture"; Brooke, "Genre Theory," 372. ${ }^{45}$ Najman, Seconding Sinai, 41-69. 
and Pseudo-Ezekiel. ${ }^{46}$ It also seems that types of rewriting that are not clearly interpretive, such as reproducing an extended section of text verbatim, or using the language of a specific scriptural passage to formulate something new, like the Temple Scroll does for its nonscriptural firstfruits festivals, can be explained by viewing them as a way of further anchoring the rewritten text in the same discourse as the original. ${ }^{47}$

This final element of my sketch of a generic description points especially to the complexity of the issues surrounding genre and genre expectations in rewritten texts. The attempt to locate a new text within an existing authoritative tradition is, in effect, the attempt to place this new work within an existing genre. The authors of most of the rewritten texts considered here, I would argue, wanted their texts to be read as the same kind of text as the text that formed the basis for the rewriting. That is, they were seeking to conform to the genre expectations of their audience. In the late Second Temple period,

${ }^{46}$ As Collins notes, each of these texts claims authority in a slightly different way ("Epilogue," 427). While the specific features of each text must be taken into account, I believe that the common strategy of being located, one way or another, within the same discourse as the texts they rewrite constitutes a significant unifying element.

${ }^{47}$ See Bernard M. Levinson and Molly M. Zahn, "Revelation Regained: The Hermeneutics of כי כם in the Temple Scroll," DSD 9 (2002): 295-346; Molly M. Zahn, "New Voices, Ancient Words: The Temple Scroll's Reuse of the Bible," in Temple and Worship in Biblical Israel (ed. John Day; LHB/OT 422; London: T\&T Clark, 2005), 435-58. On the use of Scripture in the Temple Scroll's firstfruits festivals, see Zahn, Rethinking Rewritten Scripture, 206-18. 
readers expected certain things of texts labeled "Torah" or "prophecy," notably ancient origins and a link to an exemplary figure from Israelite history. ${ }^{48}$ The authors of rewritten works satisfied that expectation.

One might ask why, then, we don't simply regard Jubilees, the Temple Scroll, and other rewritten works as belonging to a category such as "Torah" or "prophecy." ${ }^{\text {"99 }}$ On one level such a designation may be suitable. In particular, it may accurately capture how these works were perceived - it may perhaps constitute a correct genre label from the point of view of the audience. However, I think the interpretive aspect of rewritten texts, as outlined above, constitutes a key element of their purpose and separates them from other texts that might be considered "prophecy" or "revealed." Although this interpretive element is not acknowledged by the texts themselves, they nevertheless aim not just to supplement or expand prior tradition, but to interact with, correct, and improve it in specific ways. ${ }^{50}$ Furthermore, I would argue that the interpretive nature of these texts

${ }^{48}$ See John Barton, Oracles of God: Perceptions of Ancient Prophecy in Israel after the Exile ( $2^{\text {nd }}$ ed.; Oxford: Oxford University Press, 2007), 59-62; for further reflection on this issue see Najman, "Reconsidering Jubilees," 194.

${ }^{49}$ In "Reconsidering Jubilees," Najman in fact suggests that we should place Jubilees "within the traditions of biblical prophecy" (p. 192), a categorization rooted in Jubilees' self-presentation that Najman notes has tended to be overlooked in favor of terms like "new Torah" or "Rewritten Scripture" or even "interpretation."

${ }^{50}$ I agree with Najman that categorizing Jubilees as "interpretation" ignores the text's self-presentation and does not adequately describe the work (see "Reconsidering 
gave them a function in the community distinct from other ancient, revealed texts that were less directly engaged in rewriting: they provide specific new ways of reading existing tradition.

The result of the combination of the interpretive element of Rewritten Scripture texts with their location in an existing authoritative discourse is, in effect, a difference between the nature of the genre expected by the audience and the nature of the genre employed by the producers of these texts. The audience may well not have perceived rewritten works as "rewritten" or as "interpretive” at all; Jubilees was likely seen as just as "prophetic" as 1 Enoch or Deuteronomy. ${ }^{51}$ Yet rewriting and interpretation are, I believe, key elements of the genre as seen from the perspective of the author. ${ }^{52}$ The Jubilees," 192). In my mind, however, a characterization of Jubilees that gives no place to interpretation (to be clear, I do not think this is what Najman has in mind) overlooks a salient feature of the text.

${ }^{51}$ Similarly, see Jonathan G. Campbell, “'Rewritten Bible' and 'Parabiblical Texts': A Terminological and Ideological Critique," in New Directions in Qumran Studies (ed. Jonathan G. Campbell, William John Lyons, and Lloyd K. Pietersen; LSTS 52; London: T\&T Clark, 2005), 43-68, at p. 49.

${ }^{52}$ I am presuming here that the authors of rewritten texts were conscious that they were interacting with an existing authoritative text. It may be possible to contest this presumption in some individual cases_-perhaps an author may have incorporated an existing tradition without recognizing that tradition's interpretive nature. Yet I have difficulty believing that authors could have produced the extensive, largely sequential, 
authors of rewritten texts satisfy their audience's generic expectations, but not perhaps in the way their audiences would expect.

Putting together all three of these elements, I would propose that we could profitably think of Rewritten Scripture as a genre that functions to interpretively renew (update, correct) specific earlier traditions by recasting a substantial portion of those traditions in the context of a new work that locates itself in the same discourse as the scriptural work it rewrites. From a rhetorical point of view, what these texts do is provide a version of past tradition that better reflects the concerns and ideology of their community. The genre, so defined, enables authoritative tradition to continue to speak to the present community directly; it provides a lens for reading existing tradition by expanding the contents of that tradition. ${ }^{53}$

$$
* * *
$$

and detailed hermeneutical engagement with existing Scripture that we find in, e.g., Jubilees or the Temple Scroll, without an awareness that they were re-telling or representing that material. Kugel notes the presence in "Rewritten Bible" of both highly conscious (Jubilees) and possibly unintentional or unconscious rewriting; see Kugel, Traditions of the Bible, 23, and Kugel's earlier proposal of a widely-distributed, orally transmitted collection of "standard explanations of various problems and peculiarities in the biblical text" in In Potiphar's House: The Interpretive Life of Biblical Texts (New York: HarperCollins, 1990), 264-67 (quotation from p. 266).

${ }^{53}$ See Najman, "Reconsidering Jubilees," 202. 
Several concluding observations are in order regarding this tentative proposal. First, what distinguishes Rewritten Scripture from a generic perspective is not any one single element, but the combination of elements. ${ }^{54}$ There are other types of works that use some of the same techniques of scriptural reworking, but they are either scriptural copies that do not constitute new works, or works that do not try to position themselves within the same "discourse" as the texts they rewrite. ${ }^{55}$ On the other hand, as I noted just above,

${ }^{54}$ That genres or other categories are marked by a variety of different types of features in combination, which cohere into a "Idealized Cognitive Model" or ICM, is a prominent feature of the prototype theory approach to genre discussed above. I thank Ben Wright for pointing out this connection.

${ }^{55}$ It should not be entirely surprising —indeed, perhaps expected in light of the above discussion of genre- that the boundaries between these categories may sometimes be difficult to determine, or that borderline cases may resist firm classification. In part, this is due to the fragmentary preservation of some texts. On the other hand, the possibility should be considered that particular textual units might have functioned in different ways at different points in their history. For example, a unit that was originally composed as part of an expanded edition or copy of a scriptural book may subsequently be incorporated into a "Rewritten Scripture" composition; or a rewritten passage that originally circulated independently (or as part of a new composition) may at some point have been folded back into an expanded copy of the scriptural text it rewrites. In other words, we have at our disposal only particular moments or snapshots in textual history, and we would do well to keep in mind that any generic landscape that we identify would 
other kinds of texts use pseudepigraphy or other means to locate themselves within the same discourse as other scriptural texts held to be ancient, but they lack the interpretive element that comes from the sustained rewriting. It is at the point of intersection of all these various options that the distinctiveness of Rewritten Scripture emerges.

Second, those familiar with the discussion in recent years will have noted that the definition for Rewritten Scripture that I propose is not terribly new, or new at all: Rewritten Scripture as independent works characterized by interpretation and sustained rewriting is basically the definition proposed by Moshe Bernstein in his 2005 article. ${ }^{56}$ But this consideration of Rewritten Scripture in light of genre theory allows us to be more precise about the function(s) and possible significance of this category, as well as how it relates to other, similar categories: where Rewritten Scripture fits in the web of different strategies and discourses in Second Temple Judaism.

have looked different at a different stage of textual development. I am grateful to Andrew Teeter for raising this issue.

${ }^{56}$ Bernstein, "Rewritten Bible," 195. These same features are present in Alexander's 1988 list of nine "principle characteristics of the 'rewritten Bible' genre” ("Retelling the Old Testament," 116). My greatest difficulty with Alexander's generally excellent analysis is that, as has often been noted, he limits "rewritten Bible" to narrative. The result is the elimination of a whole host of potential non-narrative examples of the genre (most notably the Temple Scroll), as well as what I would regard as undue emphasis on the sequential reproduction of the earlier text. 
Third, we must keep in mind the fuzziness and flexibility of genres as they are now conceived. This definition should be understood as allowing for considerable flexibility, a flexibility most readily conceptualized in light of the prototype model mentioned earlier. The texts that constitute the most prototypical members of the group, in my mind, are Jubilees and the books of Chronicles, with the Genesis Apocryphon and the Temple Scroll close behind. ${ }^{57}$ Less clear cases can still be associated with Rewritten Scripture, but with the recognition that they do not employ the genre as clearly or to the same extent as more "prototypical" examples like Jubilees. For example, Pseudo-Ezekiel may be less prototypical in that it appears to deal only with a few selected visions-but it clearly shares the interpretive aspect and the location in the same discourse as the text it rewrites. Josephus's Antiquities or the pentateuchal targumim constitute other marginal cases: both share the sustained engagement with the scriptural text and the element of interpretation, but their self-presentation—Josephus writing in his own words, and the targumim as translations with liturgical functions - differs somewhat from other exemplars of the category.

Finally, along the same lines, we should keep in mind the need to hold multiple perspectives in view simultaneously. As noted above, texts can and do belong to more than one genre, and to group a text with other "Rewritten Scripture" texts is not to deny its participation in one or more other genres, each with their own functions and systems

${ }^{57}$ Here I should stress that we do not, of course, know whether these same texts would have been recognized as prototypical examples by the Second Temple scribes who produced them and similar texts. 
of expectations. I do not think this means that we must, as Brooke and Collins suggest, think of "Rewritten Scripture" as operating on a broader level or higher order of abstraction than more formally bound genres like law or apocalypse. ${ }^{58}$ Rather, it seems better to imagine the different generic proclivities of a single text as overlapping spheres:

58 The situating of Rewritten Scripture as a sort of "umbrella term" (in Collins's words) seems to raise the question for both Brooke and Collins whether Rewritten Scripture really constitutes a genre at all. This can be seen through Brooke's proposal that Rewritten Scripture is a "meta-genre" (thus, in some way not quite the same thing as a genre; see Brooke, "Books of Chronicles," 41, 47), and in the following statement of Collins: "The question arises then whether the word genre is more appropriately used at the level of the umbrella term that embraces the different kinds of rewriting, or whether we should rather think of the relevant texts as narratives, legal texts, prophecies, etc." ("Epilogue," 428). That is, Collins here allows that we could regard the "umbrella term" Rewritten Scripture as a genre, but implies that perhaps it is better, generically speaking, to identify rewritten texts according to more formally defined genres such as law and narrative. As noted above, however, I regard this as a case of both/and rather than of either/or: a text like the Temple Scroll could be said to belong to the genre of law and to the genre of Rewritten Scripture. See also Collins's even more recent comment that Rewritten Scripture "is not strictly a literary genre"; "Changing Scripture," in Changes in Scripture: Rewriting and Interpreting Authoritative Traditions in the Second Temple Period (ed. Hanne von Weissenberg et al.; BZAW 419; Berlin: De Gruyter, 2011), 2345 , at p. 31 . 
in the definition proposed here, Rewritten Scripture is not really any "broader" or less concrete than other genres. Instead, the features that members of the category tend to share are functional and relational in nature as opposed to involving specific contents or textual structures; they thus create a group that cuts across categories of form or content. Although there are situations that for practical reasons may require identification of one primary genre for each text—-such as editions, translations, or lists like that of Lange and Mittmann-Richert in DJD 39—we must guard against the old tendency for generic labels to function as pigeonholes: we should work to ensure that multigeneric texts are studied in light of all the different genres in which they participate. ${ }^{59}$

All in all, I hope to have shown that new ways of thinking about genre have a great deal to contribute to the study of Second Temple texts that rewrite prior Scripture. Modern genre theory raises questions about nearly all aspects of texts: the goals and ideologies of their authors; the social, cultural, and literary backdrop against which they were produced; and the worldviews and expectations of their readers - the initial or intended audiences as well as readers, like ourselves, who come much later. Of course one can address many of these issues without explicitly engaging questions of genre at all. Genre studies, however, provides a fruitful model for integrating textual, historical, and cultural observations. Thinking about Rewritten Scripture as a genre thus provides an

${ }^{59}$ Armin Lange with Ulrike Mittmann-Richert, "Annotated List of the Texts from the Judaean Desert Classified," in The Texts from the Judaean Desert (ed. Emanuel Tov; DJD 39; Oxford: Clarendon, 2002), 115-64. 
additional angle for articulating key questions about the role and function of these texts in Second Temple Judaism. 